\title{
Oh no - it's an expert patient!
}

\section{Gill Wakley}

\section{Introduction}

For many doctors and nurses, the term 'Expert Patient' conjures up a scary vision of someone coming in with a sheaf of computer printouts, a newspaper cutting or with a 'friend' from the local support group. They sit down with determined expressions and you feel your hackles rising as they demand access to scarce services, obscure investigations or unproven treatment. Think again - it might mean someone who has been on the Expert Patient Programme (EPP), who has learnt how to be more selfconfident, is better able to manage their condition and is consulting for advice on how to best manage a problem.

\section{Expert Patient Programme}

The Expert Patient Programme is a course for people with long-term conditions. You all know someone with a longterm condition: pelvic pain, endometriosis, polycystic ovarian syndrome, vulvodynia, urinary incontinence, herpes, as well as depression, diabetes and cancer. The course is delivered by trained and accredited tutors who are also living with a long-term health condition. It aims to give people the confidence to take more responsibility and self-manage their health, while encouraging them to work together with health and social care professionals.

The comparison of before and after measures showed that, 4-6 months after completing the course, general practitioner (GP), outpatient and A\&E attendances decreased but pharmacy visits increased. Results from the UK have not been as dramatic as those from the USA. ${ }^{1-3}$ The better communication with health care professionals leads to more effective use of treatment and care, despite a smaller reduction in consultations in the UK. This will disappoint the government looking to decrease the use of the National Health Service, but please those who recognise that people with long-term conditions often get a raw deal! People who have been on an EPP course have reported an increase in:

- Self-confidence

- Control of their condition

- Feeling of well-being

- Ability to cope

- Their belief that they can do something to change their health behaviour

- Exercise and relaxation

- Quality of consultations with doctors

and a decrease in:

- Pain and fatigue

- Anxiety, depression and breathlessness

- Visits to GPs

- Outpatients visits

- A\&E admissions

- Hospital admissions.

\section{EPP course content}

The EPP course is based upon the Chronic Disease SelfManagement Program (CDSMP) developed and researched over the past 20 years at Stanford University, CA, USA.

J Fam Plann Reprod Health Care 2009; 35(3): 199

Abergavenny, UK

Gill Wakley, MD, FFSRH, Retired Professor of Primary Care Development and Freelance Writer

Correspondence to: Dr Gill Wakley. E-mail: gillwak@aol.com
The programme has been used in Australasia, Europe, USA and by a number of patient bodies in the UK.

EPP courses are run over six consecutive weekly sessions of $2^{1 / 2}$ hours in suitable venues in local communities and are free of charge. Each week, two volunteer tutors lead 8-16 participants through structured course material delivered from a scripted manual. This covers using a toolbox of techniques to break the symptom cycle of pain, fatigue, difficult emotions such anger, anxiety and depression, tense muscles and shortness of breath. Topics included are:

- Managing symptoms such as pain and fatigue

- Dealing with anger, fear and frustration

- Coping with stress, depression and low self-image

- Eating healthily

- Learning relaxation techniques and taking regular exercise

- Improving communication with family, friends and health professionals

- Planning for the future.

Each week individuals in the group identify something they want to do and make an action plan. They report back and the group looks at how to tackle any problems in achieving the action plan. Participants on the course use a course manual called Self-management of Long-term Health Conditions. This is based on the book used at Stanford University and has been adapted for use in England or in Wales.

The original programme has been expanded to include courses for carers and for specific illnesses such as arthritis, diabetes or depression. The courses do not provide any health condition or treatment information, and do not look at specific health needs. The tutors are selected during a tough but supportive training course. Each tutor practises delivering parts of the course, while other tutors - only too convincingly - play difficult participants. Quality assurance is maintained by frequent assessments of tutors delivering courses.

What makes the EPP special is the sharing of skills and experience with people who have to deal with the same problems as each other. Perhaps the biggest gain from the course is learning to specify what the problem is, and working out an action plan to tackle it. Anyone with a longterm health condition can self-refer themselves. If you know a patient who would benefit from attending an EPP course, you can give them the information and encourage them to contact their local EPP team, or you can refer them directly to your local EPP contact. 4,5

\section{Statements on funding and competing interests \\ Funding None identified.}

Competing interests None identified.

\section{References}

1 Barlow JH, Sturt J, Hearnshaw H. Self-management for people with chronic conditions in primary care: examples from arthritis, asthma and diabetes. Health Educ J 2002; 61: 365-378.

2 Cooper J, Jones R, Thompson J. Expert patients are more enjoyable. Practice Nursing 2002; 13: 146-147.

3 Griffiths C, Foster G, Ramsay J, Eldridge S, Taylor S. How effective are expert patient (lay led) education programmes for chronic disease? BMJ 2007; 334: 1254-1256.

4 Expert Patients Programme Community Interest Company website. http://www.expertpatients.co.uk/public/default.aspx [Accessed 31 May 2009].

5 Expert Patients Programme Wales website. http://www.wales. nhs.uk/sites3/home.cfm?orgid=537 [Accessed 31 May 2009]. 